\title{
Application of Electron Microscopy in the Development of a Decapsulation Methodology for Microcircuits with Copper On-Chip Passive Devices.
}

\author{
Jake Schaper, Thomas Barbieri, Rose Stone \\ Motorola Semiconductor Products Sector, Arizona Product Analysis Lab \\ 2100 E. Elliot Road, Tempe, AZ 85284
}

One of the major hurdles to consider when developing new materials for IC manufacturing is the need to selectively deprocess the final product after it is packaged. One of Motorola's newest devices that uses SiGe:C and copper inductor metal layers in high frequency devices for RF applications is one such device for consideration, see Figure 1.

An integral part of quality assurance in the semiconductor industry is the ability to "deprocess" parts that have failed in the field or at any point after final manufacturing. This involves removing the mold compound and any final protective coating to expose the encapsulated die. Oftentimes, continued operation of the part is required after decapsulation in order to assist the failure analysis engineer in determining the root cause for failure of the part. Historically, the circuit within the molded package is well protected by a final passivation glass, and any exposed metal is aluminum-based and acid tolerant. However, Motorola's newest RF circuits contain copper lines and structures protected only by a thin polymeric coating. Circuit continuity and function must be maintained after removing the mold compound and protective polymer layer. The difficulty in complying with this constraint lies in the fact that two of the most common etching agents for mold compound removal are nitric and sulfuric acids (two acids which also etch copper), and the copper lines are not protected by any passivation glass compounds.

The Arizona Product Development and Analysis Laboratory (AZ PDAL) within Motorola has successfully developed a procedure for removing the mold compound and polymeric coating to expose the die surface while maintaining the structural and electrical integrity of the final copper layer. Electron microscopy played an important role in the development and verification of this new procedure. Surface exposure and copper line integrity was confirmed using SEI inspection. The high image contrast provided by BSE imaging was utilized for viewing copper line cross-sections and obtaining area measurements from these cross-sections, and EDS analysis provided an effective method for evaluating the nature and composition of a substance that developed during removal of the encapsulation materials.

Controlled experiments that varied acid concentrations, time, temperature, rinse times, and rinse liquids were performed. The results of the experiments showed that standard acids were compatible with the new materials, but final rinse treatments were critical to the ability to perform subsequent circuit analysis. The etch process generated copper-based compounds that were insoluble with standard acetone and alcohol rinses. A final rinse with de-ionized water was investigated due to high solubility of the copper compound in water. Figures $2 \mathrm{a}$ and $2 \mathrm{~b}$ show a typical copper feature and its appearance after a successful selective decapsulation using the established procedure. Electrical 
performance before and after decapsulation was also evaluated. RF levels typically deviated by less than $3 \%$ from control samples. Cross-sectional dimensions of post decapsulated features remained within acceptable limits. In addition, acid exposure tolerance of small pitch dimensions was extremely good with respect to adhesion.

1. D. Jones, Principles and Prevention of Corrosion, Macmillan, 1992.

2. Handbook of Chemistry and Physics, CRC Press, 69th Ed. 1988-1989.
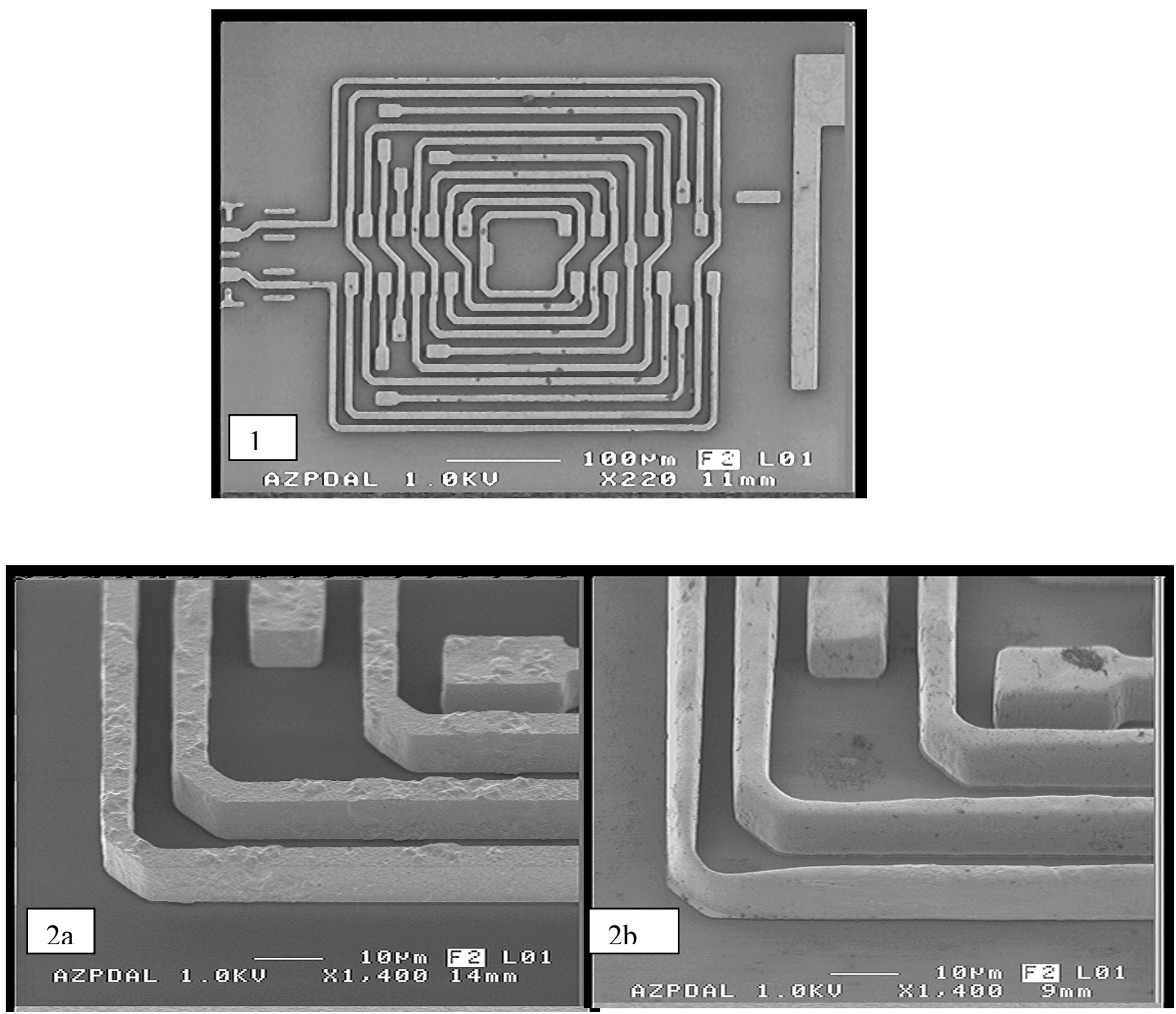

FIGURE 1. Example of an on-chip copper component, a transformer.

FIGURE 2a,2b. Typical appearance of a copper feature before encapsulation and after decapsulation, respectively. 